\title{
Correction to: Irvingia gabonensis: Phytochemical Constituents, Bioactive Compounds, Traditional and Medicinal Uses
}

Gustav Komla Mahunu, Lydia Quansah, Haroon EIrasheid Tahir, and Abdalbasit Adam Mariod

\section{Correction to:}

Chapter 21 in: A. A. Mariod (ed.), Wild Fruits:

Composition, Nutritional Value and Products, https://doi.org/10.1007/978-3-030-31885-7_21

In the original version of this book, Chapter 21 was inadvertently published with the corresponding author's name as "Lydiah Quansa". The author's name has now been corrected to "Lydia Quansah".

The updated online version of this chapter can be found at https://doi.org/10.1007/978-3-030-31885-7_21 